\title{
Factorial structure of cognitive activity using a neuropsychological test battery
}

\author{
A. Ardila', M. Rosselli² and J.R. Bateman ${ }^{3}$ \\ 1/nstituto Colombiano de Neuropsicologia, ${ }^{2}$ Hospital San Juan de Dios, and ${ }^{3}$ Fundación \\ Universitaria "Konrad Lorenz", Bogotá, Colombia
}

\begin{abstract}
A general neuropsychological test battery was assembled and individually given to a 98-subject sample, aged 11-12 years old. The battery included some basic and common tests routinely used in the evaluation of language, memory, spatial abilities, concept formation, and praxic abilities. Twenty-five different scores were calculated. A factor analysis with varimax rotation disclosed nine different factors, accounting for about $70 \%$ of the variance. Factor I was measured by a Sequential Verbal Memory test and Verbal Fluency subtests ("verbal factor"). Factor II was measured by the Wechsler Memory Scale Visual Memory subtests (immediate and delayed reproduction), and the Rey-Osterrieth Complex Figure (copy and immediate reproduction) ("non-verbal memory and constructional factor"). Factor III was measured by the WMS Logical Memory subtests (immediate and delayed; "verbal memory factor"). Factor IV was associated with fine movements (tapping subtests, right and left hand; "fine movements factor"). Factor $V$ was specially measured by the Information subtest of the WMS and the Boston Naming Test ("verbal knowledge"). Factor VI represented a "praxic ability factor" (ideomotor praxis tests). Delayed Associative Learning subtest measured Factor VII; and Digits measured Factor VIII. Factor IX was a "mental control factor" (Mental Control subtest of the Wechsler Memory Scale). The implications of these results to theories relating to the structure of cognitive activity are discussed.
\end{abstract}

Keywords: Cognitive activity - Factorial analysis - Neuropsychological assessment

\section{INTRODUCTION}

Different factorial studies of general intelligence have been described in the psychological literature (e.g. Guilford, 1967; Cattell, 1971; Matarazzo, 1972). Guilford $(1967,1968)$ and Guilford and Hoepfner (1971) proposed a three-dimensional classification of intelligence, consisting of contents (letters, numbers, words, and behavioral descriptions), operations (memory, evaluation, convergent thinking, and divergent thinking), and products (units, classes, relations, systems, transformations, and implications). According to Guilford, 120 different intellectual abilities could be distinguished. Cattell (1971) distinguished between "fluid intelligence" (corresponding to and reflecting a pattern of neurophysiological and incidental learning influences), and "crystallized intelligence" (highly sensitive to each person's unique cultural, educational and environmental experiences).

Most often, a four-factor structure has been found in the WAIS (Matarazzo, 1972). Factor I ("verbal comprehension") is measured by Information, Vocabulary, Similarities, and Comprehension subtests. Factor II ("perceptual organization") is measured with Object Assembly, Block Design, Picture Completion, and Picture Arrangement subtests. Factor III ("freedom of distractibility") is specially measured

(C) 1994 Rapid Communications of Oxford Ltd with the Digit-Symbol subtest. A fourth (albeit weaker) factor is measured by the Arithmetic subtest (Cohen, 1957).

In the field of neuropsychology, factorial analysis has been applied to some specific tests and scales directed to measure single cognitive abilities. The Wechsler Memory Scale (WMS) is a good example. To date, several factor-analytic studies with the WMS have been published, usually reporting a two-factor structure ("general memory" and "attention" factors) (Wechsler, 1987; Bornstein and Chelune, 1988; Roid et al., 1988; Ardila and Rosselli, in press). However, Elwood (1991) analyzed the factor structure of the revised WMS in a clinical sample and observed that only a single general memory component accounted for $54 \%$ of the variance; a second factor which contributed $9.4 \%$ of the total variance was found only after I.Q. scores were included. Ardila and Rosselli (in press) used the original WMS version, but included delayed recall for the Logical Memory, Visual Reproduction and Associative Learning subtests. One general memory component accounted for $51 \%$ of the variance. A second factor reported by Wechsler (1987) as an "attentional factor" was also found. Further, Ardila and Rosselli have observed a 
third, very weak factor, related to verbal memory, specially measured by means of the Associative Learning subtests ("verbal memory factor"). These results with the WMS are very similar to the results obtained by Wechsler (1987), Bornstein and Chelune (1988), and Elwood (1991) using the revised WMS. It seems probable therefore that there is not too much difference between the WMS and the revised WMS factor structure.

Very few factorial analyses of neuropsychological battery tests have been described in the literature. Ostrosky et al. $(1985,1986)$, using a neuropsychological battery test derived from Luria, found three main factors. Factor I included complex linguistic aspects, reading and calculation ("verbal factor"); Factor II included a large number of motor tasks, related in particular to motor programming ("motor programming factor"); and Factor III basically comprised two movement coordination tasks as well as certain aspects of memory and complex aspects of language comprehension. However, to perform the factorial analysis, the authors selected only those tests sensitive to sociocultural effects, and not the whole battery test. Recently some new attempts to apply factor analysis to different neuropsychological tests have been presented (e.g. Haut et al., 1992; Wilhem and Franzen, 1992).

Factor analysis represents a strong and relatively sophisticated statistical tool to measure research, and permits the deduction of underlying factors accounting for variance in individual tests. Commonality, and in consequence, "relative distance" among different subtests can be determined. The purpose of this research was to attempt a further step in the component analysis of cognitive activity. A general neuropsychological battery test was assembled and individually given to a 98 -subject sample. The battery included some basic and common tests routinely used in the diagnosis of language, memory, spatial abilities, concept formation, and praxic abilities. Normative results of this battery test have been presented elsewhere (Ardila and Rosselli, 1992, in press).

\section{METHODS}

\section{Subjects}

Ninety-eight 11-12 year old normal schoolchildren (49 boys and 49 girls) were selected. The subjects included in the sample corresponded to three socioeconomic groups: high, middle, and low. For each socio-economic group, two different schools were taken. Schools included in this study were carefully informed about the purposes of the research. Al- though the children were randomly selected from a list presented by the school principal, all of them voluntarily agreed to participate in the testing. All the subjects were considered at school as "normal children". All subjects were Colombians living in Bogotá (population around 5500000 inhabitants), and were native Spanish speakers. All children were in the fifth or sixth grade at school (except two children who were in the fourth grade). Distribution among different socio-economic groups was equal.

\section{Testing}

The following tests were individually given to each subject.

(1) Verbal Fluency: Semantic (VFS; animals and fruits) and Phonologic (VFP; F, A, S, and M).

(2) WMS (Wechsler, 1945). The six subtests were independently scored and analyzed: Information (INF), Orientation (ORI), Mental Control (MC), Logical Memory (LM), Digits (DIG), Visual Reproduction (VR), and Associative Learning (AL). In addition, delayed recall for Logical Memory (LMD), Associative Learning (ALD), and Visual Reproduction (VRD) subtests was included.

(3) A Sequential Verbal Memory Test, specially designed for this research (Table I). This test attempted to measure the subject's ability to sequentially memorize a series of words in two different conditions: immediate (maximum level: VMM), and delayed recall (VMD).

(4) An Ideomotor Apraxia Test adapted from De Renzi (1985), Poeck (1986), and Rosselli and Ardila (1991). Seven movements were included (a military salute, waving goodbye, calling somebody with the hand, saying "no" with the hand, hammering a nail, brushing his/her teeth, and using scissors), first with the left hand (PLH) and then with the right hand (PRH).

(5) The Tapping Test (Reitan and Davidson, 1974). Scores were given for the right hand (TRH) and the left hand (TLH) performance.

(6) Figure Recognition (FR). Recognition of 14 commonly drawn figures, superimposed one on another in four groups $(2,3,4$, and 5; Poppelreuter-type figures). Maximum score was 14.

(7) The Token Test (TT)-shortened version (De Renzi and Faglioni, 1978).

(8) The Wisconsin Card Sorting Test (WCST). The protocol was administered and scored according to the rules of the WCST Manual (Heaton, 1981). Two different scores were used: Categories Achieved (WCA) and Correct Responses (WCR). 
TABLE I. Sequential Verbal Memory test

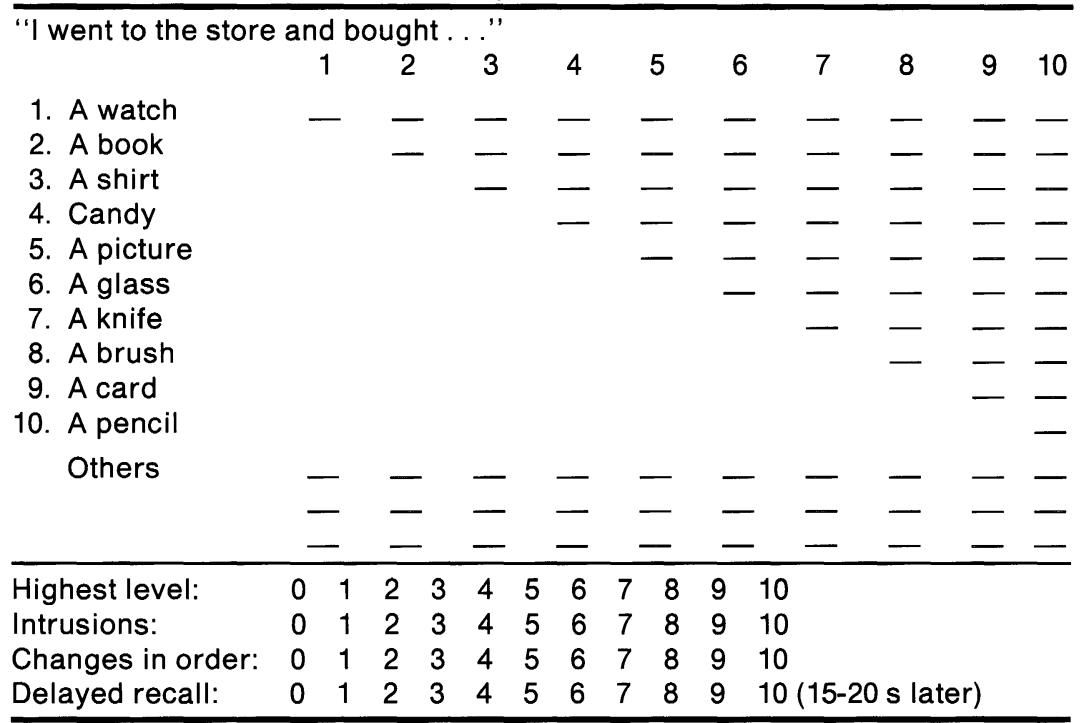

Instructions. Say to the subject: "Please, repeat what I am going to say". Begin with one-word level ("I went to the store and bought a watch"). If repeated, write number 1 in the upper left space. Move to two-words level ("I went to the store and bought a watch and a book"). Write 1 and 2 in the corresponding spaces, according to the answering order; and so on. Write the non-presented words in the spaces "Others". When the subject fails at a particular level (because of omissions or changes in the order), this level is repeated. If the subject fails again, the test is stopped. Highest level is the maximum number of words correctly repeated without mistake (either in the first or second presentation).

(9) The Boston Naming Test (BNT) (Kaplan et al., 1983). The Spanish version (Goodglass and Kaplan, 1983) was adapted to the idiosyncracies of the Spanish language spoken in Colombia.

(10) The Rey-Osterrieth Complex Figure, copy (CFC) and immediate memory (CFM; Osterrieth, 1944). Subjects were required to copy the figure placed in front of them on a plain piece of paper. There was no time limit. When the subject finished copying the figure, both the design and the subject's copy were removed and the subject was asked to draw the figure from memory. Both the copy and the memory designs were scored considering 18 units separately (Taylor, 1959; Lezak, 1983). Maximum score was 36 .

\section{RESULTS}

Means and standard deviations for the 25 test scores were calculated. Results are presented in Table II. It is observed that performance at 11-12 years approaches the performance expected in young normal adults (Lezak, 1983; Spreen and Strauss, 1991; Ardila et al., 1994).
An intercorrelation matrix of the different test scores is shown in Table III. Forty-four out of 300 correlations reached a statistical level of significance. Some of the test scores presented a complex intercorrelation system (e.g. Logical Memory); others presented very few significant correlations (e.g. Associative Learning, Delayed condition).

Both Verbal Fluency subtests (Semantic and Phonologic) significantly correlated with WMS Logical Memory subtest, and with the Sequential Verbal Memory Test (Maximum Level and Delayed Reproduction). Correlation between both conditions (Semantic and Phonologic) was $0.50(p<0.01)$. Additionally, Semantic (but not Phonologic) Verbal Fluency correlated with WCST (Correct Responses). Surprisingly, both Verbal Fluency subtests (although only Phonological Verbal Fluency subtest at a statistically significant level) negatively correlated with the WMS Orientation subtest.

The different WMS subtests behaved in a heterogeneous way. The WMS Information subtest correlated with Orientation, Logical Memory, WCST (Categories Achieved), but especially with the BNT score $(r=0.46 ; p<0.01)$. The Orientation subtest negatively correlated with Delayed Associative Learning 
TABLE II. Means and standard deviations found in the different neuropsychological tests in the 98-subject sample

\begin{tabular}{lrr}
\hline Test & Mean & S.D. \\
\hline Verbal Fluency & & \\
Semantic (VFS) & 26.67 & 9.51 \\
Phonologic (VFP) & 29.64 & 8.87 \\
WMS & & \\
Information (INF) & 5.49 & 0.69 \\
Orientation (ORI) & 4.94 & 0.28 \\
Mental Control (MC) & 6.19 & 1.64 \\
Logical Memory (LM) & 12.84 & 3.06 \\
Digits (DIG) & 9.50 & 1.42 \\
Visual Reproduction (VR) & 9.52 & 2.21 \\
Associative Learning (AL) & 18.20 & 2.26 \\
Delayed Logical Memory (LMD) & 12.67 & 2.90 \\
Delayed Associative Learning (ALD) & 7.49 & 2.32 \\
Delayed Visual Reproduction (VRD) & 8.70 & 2.41 \\
Verbal Memory & & \\
Maximum (VMM) & 6.85 & 2.37 \\
Delayed Recall (VMD) & 6.45 & 2.36 \\
Praxis & & \\
Left Hand (PLH) & 6.49 & 0.78 \\
Right Hand (PRH) & 6.52 & 1.04 \\
Tapping Test & & \\
Right Hand (TRH) & 44.11 & 11.20 \\
Left Hand (TLH) & 33.79 & 8.62 \\
Figure Recognition (FR) & 13.20 & 1.15 \\
Token Test (TT) & 35.03 & 1.90 \\
WCST & & \\
Correct Responses (WCR) & 66.16 & 9.83 \\
Categories Achieved (WCA) & 5.67 & 0.86 \\
Boston Naming Test (BNT) & 48.00 & 4.80 \\
ROCF & 28.66 & 4.77 \\
Copy (CFC) & 20.52 & 5.97 \\
Memory (CFM) & & \\
\hline & & \\
\hline
\end{tabular}

TABLE IV. Factor analysis of the neuropsychological battery test

\begin{tabular}{lccc}
\hline Factor & Eigenvalue & Pct. of variance & Cum. Pct. \\
\hline I & 3.560 & 14.2 & 14.2 \\
II & 3.218 & 12.9 & 27.1 \\
III & 2.445 & 9.8 & 36.9 \\
IV & 1.591 & 6.4 & 43.3 \\
V & 1.508 & 6.0 & 49.3 \\
VI & 1.386 & 5.5 & 54.8 \\
VII & 1.342 & 5.4 & 60.2 \\
VIII & 1.241 & 5.0 & 65.2 \\
IX & 1.111 & 4.4 & 69.6 \\
\hline
\end{tabular}

and Verbal Fluency (above), and positively only with Figure Recognition $(r=0.30 ; p<0.05)$. Mental Control correlated with the BNT and the Tapping Test (right hand). The Logical Memory subtest presented a high number of statistically significant correlations: with Associative Learning (both conditions), BNT,
Verbal Fluency (both conditions), and Information. Correlation between Logical Memory and Delayed Logical Memory was $0.63(p<0.01)$. Digits correlated with Associative Learning and Figure Recognition. Visual Reproduction subtest correlated with Rey-Osterrieth Complex Figure (copy; $r=0.41$; $p<0.01$ ), but negatively with Figure Recognition $(r=-0.25 ; p<0.05)$. Correlation between Visual Reproduction scores and Delayed Visual Reproduction scores was Logical Memory and Digits). Correlation between Associative Learning and Delayed Associative Learning was non-significant. Delayed Associative Learning correlated with WCST (Correct Responses), and negatively with Orientation.

The Sequential Verbal Memory Test (both conditions) correlated with Verbal Fluency subtests. For the immediate condition, a negative correlation with the Tapping Test (right hand) was observed. Correlation between immediate and delayed condition was $0.92(p<0.01)$.

Praxic Ability Test correlated only with the Token Test. Correlation between right and left hand performance was $0.56(p<0.01)$.

In the Tapping Test, besides the described associations, significant correlation with the Token Test and the WCST (Categories Achieved) was observed. Correlation between right and left hand performance was $0.60(p<0.01)$.

The Figure Recognition Test correlated with the BNT, Orientation, Digits, and Delayed Logical Memory. It negatively correlated with WMS Visual Reproduction subtest and the WCST (Correct Responses).

The Token Test correlated with the BNT, Delayed Logical Memory, Praxic Ability Test (left hand), and Tapping Test (right hand). It negatively correlated with WCST (Correct Responses).

The WCST and the BNT presented a complex set of correlations (see above). The correlation between the WCST (Correct Responses) and the BNT was $-0.33(p<0.01)$. However, for Categories Achieved score, the correlation between both tests was positive, although non-significant.

The Rey-Osterrieth Complex Figure only correlated with the WMS Visual Reproduction (both conditions). Correlation between copy score and immediate reproduction score was $0.42(p<0.01)$.

A factor analysis with varimax rotation of the neuropsychological battery test was performed. Nine different factors with eigenvalues higher than 1.00 were disclosed. These nine factors accounted for about $70 \%$ of the total variance. Table IV presents the general results of the factor analysis.

Factor I was measured by the Sequential Verbal

52 Behavioural Neurology . Vol 7 . 1994 


\begin{tabular}{|c|c|c|c|c|c|c|c|c|c|c|c|c|c|c|c|c|c|c|c|c|c|c|c|c|}
\hline Test & VFP & INF & ORI & $\mathrm{MC}$ & LM & DIG & VR & AL & LMD & ALD & VRD & VMM & VMD & PLH & PRH & TRH & TLH & FR & TT & WCR & WCA & BNT & CFC & CFM \\
\hline VFS & $0.50 \dagger$ & 0.07 & -0.17 & 0.01 & $0.25^{*}$ & 0.02 & 0.22 & 0.05 & 0.19 & 0.05 & -0.10 & $0.44 \dagger$ & $0.46 \dagger$ & 0.05 & -0.17 & -0.08 & -0.19 & -0.03 & 0.11 & $0.28^{*}$ & 0.01 & 0.13 & 0.13 & 0.03 \\
\hline VFP & & 0.19 & $-0.25^{*}$ & 0.11 & $0.33^{*}$ & 0.12 & 0.14 & 0.22 & 0.10 & 0.02 & 0.00 & $0.37 \dagger$ & $0.43 t$ & 0.08 & -0.11 & 0.06 & 0.01 & -0.04 & 0.17 & 0.01 & 0.13 & 0.22 & -0.02 & 0.12 \\
\hline INF & & & $0.26^{*}$ & 0.22 & $0.24^{*}$ & 0.01 & -0.04 & 0.17 & 0.10 & -0.06 & 0.04 & 0.01 & 0.08 & 0.08 & 0.01 & 0.12 & 0.02 & 0.20 & 0.18 & -0.08 & $0.24^{*}$ & $0.46 t$ & 0.10 & 0.11 \\
\hline ORI & & & & -0.02 & -0.04 & -0.03 & -0.13 & -0.03 & 0.01 & $-0.33 t$ & 0.09 & -0.11 & -0.05 & 0.00 & 0.00 & 0.13 & 0.15 & $0.30^{*}$ & 0.23 & -0.18 & -0.04 & 0.01 & -0.05 & -0.10 \\
\hline $\mathrm{MC}$ & & & & & 0.10 & 0.18 & -0.04 & 0.11 & 0.21 & 0.13 & -0.05 & 0.06 & 0.15 & 0.10 & 0.05 & $0.27^{*}$ & 0.17 & -0.01 & 0.13 & -0.19 & 0.06 & $0.32 \dagger$ & 0.14 & 0.10 \\
\hline LM & & & & & & 0.07 & 0.10 & $0.36 \dagger$ & $0.63 \dagger$ & 0.10 & 0.08 & 0.15 & 0.19 & -0.05 & -0.11 & 0.05 & 0.07 & 0.21 & 0.13 & 0.02 & -0.06 & $0.24^{*}$ & -0.12 & 0.04 \\
\hline DIG & & & & & & & 0.03 & $0.24^{*}$ & 0.17 & -0.03 & 0.04 & 0.18 & 0.10 & 0.00 & -0.06 & 0.05 & 0.15 & $0.28^{*}$ & 0.04 & -0.17 & 0.21 & 0.12 & -0.07 & 0.05 \\
\hline VR & & & & & & & & 0.01 & 0.10 & -0.07 & $0.65 t$ & 0.16 & 0.21 & 0.10 & 0.12 & -0.09 & -0.08 & $-0.25^{*}$ & 0.05 & 0.18 & -0.08 & 0.01 & $0.41 \dagger$ & 0.23 \\
\hline AL & & & & & & & & & 0.21 & 0.11 & 0.10 & 0.08 & 0.14 & 0.12 & 0.09 & 0.16 & 0.20 & 0.20 & 0.22 & -0.21 & 0.15 & $0.35 t$ & 0.04 & 0.12 \\
\hline LMD & & & & & & & & & & 0.09 & 0.02 & 0.15 & 0.17 & 0.11 & -0.01 & 0.10 & 0.18 & $0.25^{*}$ & $0.25^{*}$ & -0.10 & 0.04 & 0.23 & -0.12 & 0.05 \\
\hline ALD & & & & & & & & & & & 0.18 & -0.03 & -0.09 & -0.05 & -0.04 & 0.04 & 0.03 & -0.01 & -0.06 & $0.27^{*}$ & -0.07 & -0.09 & 0.12 & 0.02 \\
\hline VMM & & & & & & & & & & & & & $0.92 \dagger$ & 0.01 & -0.20 & -0.17 & $-0.24^{*}$ & -0.08 & -0.04 & 0.17 & -0.15 & 0.04 & -0.04 & 0.00 \\
\hline VMD & & & & & & & & & & & & & & 0.04 & -0.16 & -0.06 & -0.13 & -0.10 & 0.11 & 0.15 & -0.05 & 0.11 & -0.02 & 0.02 \\
\hline PLH & & & & & & & & & & & & & & & $0.56 \dagger$ & 0.17 & 0.22 & 0.05 & $0.27^{*}$ & -0.15 & 0.09 & 0.08 & 0.12 & 0.18 \\
\hline PRH & & & & & & & & & & & & & & & & 0.11 & 0.17 & 0.02 & 0.17 & -0.15 & 0.08 & 0.07 & 0.08 & 0.21 \\
\hline TRH & & & & & & & & & & & & & & & & & $0.60 \dagger$ & 0.21 & $0.39 \dagger$ & -0.10 & $0.26^{*}$ & 0.22 & 0.18 & 0.04 \\
\hline TLH & & & & & & & & & & & & & & & & & & 0.18 & 0.19 & -0.15 & $0.32 \dagger$ & $0.26^{*}$ & -0.07 & -0.03 \\
\hline$F R$ & & & & & & & & & & & & & & & & & & & 0.19 & $-0.29^{*}$ & 0.14 & $0.26^{*}$ & -0.20 & 0.07 \\
\hline$\pi T$ & & & & & & & & & & & & & & & & & & & & -0.14 & 0.05 & -0.02 & -0.04 & 0.07 \\
\hline WCR & & & & & & & & & & & & & & & & & & & & & -0.01 & $-0.33 t$ & 0.18 & -0.09 \\
\hline WCA & & & & & & & & & & & & & & & & & & & & & & 0.21 & 0.09 & 0.17 \\
\hline BNT & & & & & & & & & & & & & & & & & & & & & & & 0.09 & 0.17 \\
\hline CFC & & & & & & & & & & & & & & & & & & & & & & & & $0.42 \dagger$ \\
\hline
\end{tabular}




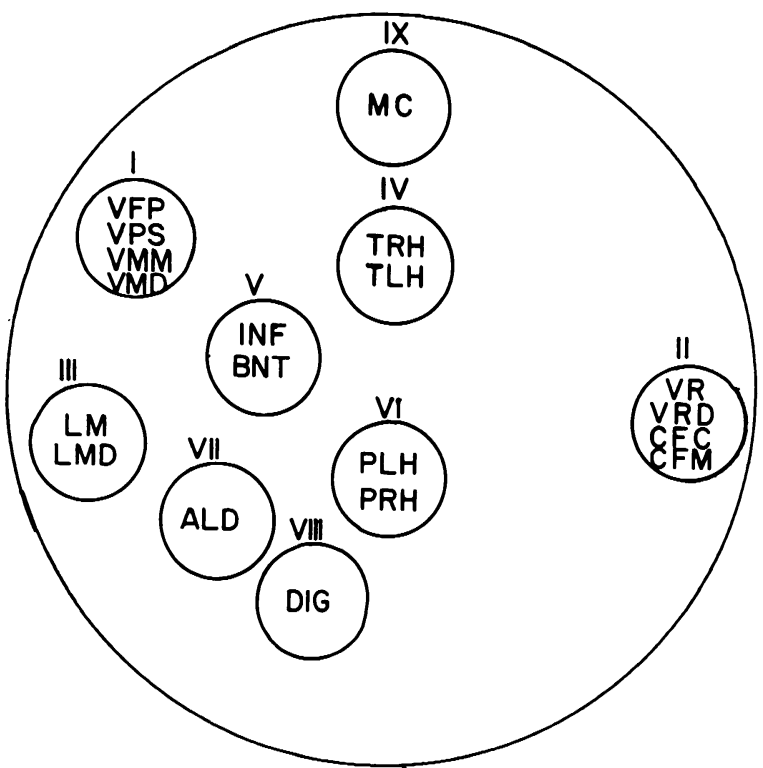

FIG. 1. Graphic representation of the nine factors disclosed in the neuropsychological test battery.

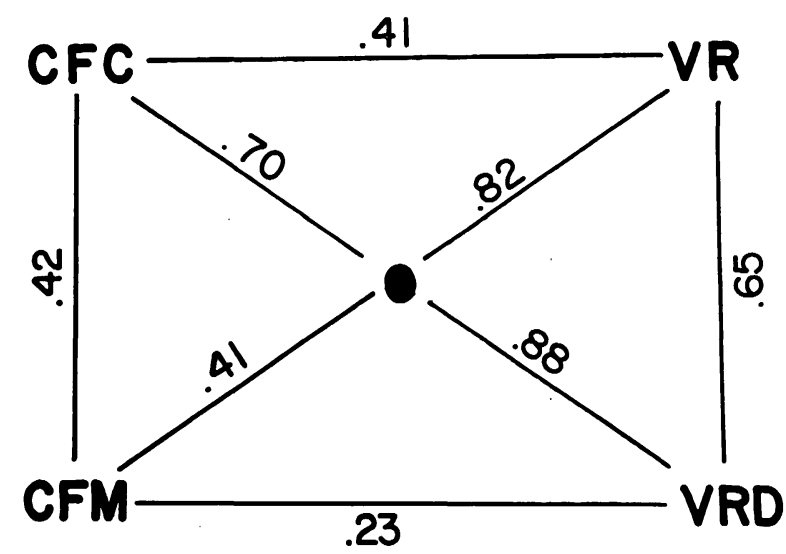

FIG. 2. Intercorrelations among the four test scores involved in Factor II.

Memory Test (Maximum Level and Delayed Recall), and Verbal Fluency subtests (Semantic and Phonologic). It represents, hence, a "verbal production" factor. Factor II was measured by the WMS Visual Memory subtests (Immediate and Delayed Reproduction), and the Rey-Osterrieth Complex Figure (Copy and Immediate Reproduction). It represents in consequence a "non-verbal memory and constructional" factor. Factor III was measured by the WMS Logical Memory subtests_(Immediate and Delayed Recall). It is in consequence a "verbal memory" factor. Factor IV was measured by the two Tapping subtests (right and left hand). This is a factor associated with fine motor movements ("fine movements" factor). Factor
$\mathrm{V}$ was specially measured by the Information subtest of the WMS and the Boston Naming Test ("verbal knowledge" factor). Factor VI represents a Praxic Ability factor (Ideomotor Apraxia Test, left and right hand; "praxic ability" factor). Delayed Associative Learning subtest measured Factor VII ("delayed associative learning" factor), and Digits measured Factor VIII ("digits" factor). And finally, Factor IX was measured almost exclusively by the WMS Mental Control score ("mental control" factor). Figure 1 illustrates the way the different tests were grouped.

The correlations between the different tests and the nine factors are presented in Table V. It is observed that for each factor, only a few test scores (some one to three) present a high (over 0.65) correlation with the factor, while the rest of the correlations are in general low. That is, only one to three test scores were significantly saturated by each factor. The level of the correlations was equivalent across the nine factors.

The most independent factor was Factor II. It was measured by two tests (WMS Visual Memory and Rey-Osterrieth Complex Figure) under the two conditions used. Correlations with other test scores were particularly low and non-significant. It represented in consequence a somewhat isolated factor. Intercorrelations among Factor II and these four scores are illustrated in Fig. 2.

\section{DISCUSSION}

Several shortcomings should be noted in the present research.

(1) The age of the subjects was low; only older children (or young pre-adolescents) were included. This is due to the fact that the research was primarily directed to the normalization of neuropsychological instruments in children (Ardila and Rosselli, 1992, in press). The factorial analysis represents a secondary analysis of the test result data. However, it is considered that performance on neuropsychological tests in 1112 year old children approaches the performance expected in young normal adults (Spreen and Strauss, 1991). Further, using an older population, the ceiling of some tests can become very low (e.g. the Token Test, the Boston Naming Test, etc.).

(2) The number of tests and subjects were relatively low (only 10 tests and 25 scores). That means that the ratio of subjects to variables was about $4: 1$, which is on the borderline of acceptability.

(3) Distribution of the tests was uneven and biased;

54 Behavioural Neurology . Vol 7 . 1994 
TABLE V. Correlations between the different tests and the nine factors

\begin{tabular}{|c|c|c|c|c|c|c|c|c|c|}
\hline \multirow[b]{2}{*}{ Test } & \multicolumn{9}{|c|}{ Factor } \\
\hline & 1 & II & III & IV & V & VI & VII & VIII & IX \\
\hline \multicolumn{10}{|l|}{ Verbal Fluency } \\
\hline Semantic (VFS) & 0.706 & 0.011 & 0.156 & -0.034 & 0.171 & -0.068 & 0.168 & -0.211 & -0.193 \\
\hline Phonologic (VFP) & 0.673 & -0.052 & 0.127 & 0.075 & 0.298 & 0.811 & 0.210 & 0.060 & -0.131 \\
\hline \multicolumn{10}{|l|}{ WMS } \\
\hline Information (INF) & 0.098 & -0.006 & 0.146 & 0.090 & 0.738 & -0.042 & -0.268 & -0.205 & 0.082 \\
\hline Orientation (ORI) & -0.167 & -0.068 & 0.064 & 0.176 & 0.070 & -0.083 & -0.797 & -0.143 & 0.041 \\
\hline Mental Control (MC) & 0.097 & -0.015 & 0.041 & 0.238 & 0.244 & 0.035 & 0.131 & 0.065 & 0.798 \\
\hline Logical Memory (LM) & 0.170 & 0.038 & 0.848 & -0.017 & 0.155 & -0.110 & 0.076 & -0.035 & -0.031 \\
\hline Digits (DIG) & 0.136 & 0.024 & 0.105 & 0.143 & -0.005 & -0.084 & 0.007 & 0.760 & 0.029 \\
\hline Visual Reproduction & & & & & & & & & \\
\hline $\begin{array}{l}\text { (VR) } \\
\text { Associative Learning }\end{array}$ & 0.798 & 0.819 & 0.772 & -0.715 & -0.172 & 0.118 & -0.210 & -0.004 & $-0.0 \% 1$ \\
\hline $\begin{array}{l}(A L) \\
\text { Delayed Logical }\end{array}$ & 0.086 & 0.039 & 0.433 & 0.149 & 0.262 & 0.158 & 0.109 & 0.325 & 0.005 \\
\hline $\begin{array}{l}\text { Memory (LMD) } \\
\text { Delayed Associative }\end{array}$ & 0.111 & 0.028 & 0.803 & 0.101 & -0.015 & 0.042 & 0.010 & 0.090 & 0.125 \\
\hline $\begin{array}{l}\text { Learning (ALD) } \\
\text { Delayed Visual }\end{array}$ & -0.098 & -0.018 & 0.212 & 0.110 & -0.071 & -0.105 & 0.714 & -0.195 & 0.165 \\
\hline Reproduction (VRD) & -0.029 & 0.879 & 0.065 & 0.064 & -0.017 & -0.040 & -0.031 & 0.100 & -0.040 \\
\hline \multicolumn{10}{|l|}{ Verbal Memory } \\
\hline Maximum (VMM) & 0.844 & 0.076 & 0.051 & -0.197 & -0.140 & -0.086 & -0.071 & 0.162 & 0.179 \\
\hline Delayed Recall (VMD) & 0.882 & 0.116 & 0.065 & -0.048 & -0.069 & -0.042 & -0.132 & 0.098 & 0.203 \\
\hline \multicolumn{10}{|l|}{ Praxis } \\
\hline Left Hand (PLH) & 0.087 & 0.036 & 0.011 & 0.169 & 0.023 & 0.840 & -0.025 & -0.011 & 0.048 \\
\hline Right Hand (PRH) & -0.188 & 0.097 & -0.025 & 0.057 & 0.023 & 0.826 & 0.007 & -0.013 & -0.011 \\
\hline \multicolumn{10}{|l|}{ Tapping Test } \\
\hline Right Hand (TRH) & -0.068 & 0.078 & 0.049 & 0.842 & 0.102 & 0.062 & -0.047 & -0.004 & 0.173 \\
\hline Left Hand (TLH) & -0.173 & -0.053 & 0.113 & 0.748 & 0.007 & 0.124 & 0.010 & 0.240 & 0.066 \\
\hline Figure Recognition (FR) & -0.167 & -0.263 & 0.404 & 0.153 & 0.274 & -0.002 & -0.258 & 0.305 & -0.157 \\
\hline Token Test (TT) & 0.185 & -0.132 & 0.303 & 0.495 & -0.038 & 0.329 & -0.291 & -0.219 & -0.015 \\
\hline \multicolumn{10}{|l|}{ WCST } \\
\hline $\begin{array}{l}\text { Correct Responses } \\
\text { (WCR) } \\
\text { Categories Achieved }\end{array}$ & 0.250 & 0.214 & -0.100 & 0.090 & -0.226 & -0.293 & 0.335 & -0.451 & -0.296 \\
\hline (WCA) & 0.014 & 0.044 & -0.195 & 0.474 & 0.441 & -0.004 & 0.114 & 0.315 & -0.364 \\
\hline Boston Naming Test & & & & & & & & & \\
\hline $\begin{array}{l}\text { (BNT) } \\
\text { ROCF }\end{array}$ & 0.065 & 0.019 & 0.211 & 0.079 & 0.686 & 0.033 & -0.044 & 0.239 & 0.278 \\
\hline Copy (CFC) & -0.019 & 0.700 & -0.199 & 0.114 & 0.273 & 0.045 & 0.148 & -0.230 & 0.132 \\
\hline Memory (CFM) & -0.034 & 0.413 & -0.021 & -0.141 & 0.447 & 0.300 & 0.166 & 0.126 & -0.010 \\
\hline
\end{tabular}

the majority of the tests were language related; neither facial recognition nor non-verbal auditory recognition tests were included. There was a limited number of perceptual tests. No somatosensory test was included. Some abilities (e.g. calculation abilities) were only indirectly measured.

Despite these shortcomings, the current factorial analysis of normal performance in neuropsychological tests, albeit tentative, allows some conclusions to be drawn.

The number of extracted factors was high. However, each factor accounted for a minor percentage of the variance. In consequence, our current neuropsy- chological tests consisted of a multifactorial battery which is not surprising considering that tests directed to measure a diversity of cognitive activities were included (language, memory, spatial abilities, concept formation, and praxic abilities).

In general, correlations between individual tests and the nine extracted factors were high (usually over 0.80 ). Only one (or two) tests measured a single factor and no test score was simultaneously and significantly saturated by two different factors.

Most factors were measured by only one or two test scores. Factor III was measured by the WMS Logical Memory subtests (immediate and delayed), 
Factor IV by the Finger Tapping subtests and Factor $\mathrm{V}$ was measured by the Information subtest of the WMS and the Boston Naming Test. Factor VI was a Praxic Ability factor (ideomotor praxis, right and left hand). The delayed Associative Learning subtest measured Factor VII; and Digits measured Factor VIII. Factor IX was correlated with the WMS Mental Control subtest. It might be supposed that single factors (and, to a certain extent, single tests) were measuring independent cognitive abilities.

It is possible that common "brain systems" underlie the performance of those tests measuring common factors. For example, in our results, Factor II ("nonverbal memory and constructional" factor) represented a quite independent and isolated factor. It could be proposed that the two tests saturated by this factor (Visual Reproduction and Rey-Osterrieth Complex Figure) were the only two tests associated with the activity of certain specific "brain systems" (according to current neuropsychological knowledge, and most likely linked with the activity of right hemisphere areas). It can also be expected that they would be impaired by lesions in this "brain system" (i.e. right hemisphere pathology). Correlations between these two tests and other tests were low and non-significant. The brain activity supporting performance in these two tests should be quite independent of the brain activity supporting performance in the rest of the battery. But both tests share the same "brain system". "Functional distance" between them is very low. Conversely, "functional distance" between these two tests and the rest of the tests is high. "Functional distance" should be understood as the commonality in the brain organization of the cognitive processes supporting their performance.

With the exception of the Visual Reproduction and Rey-Osterrieth Complex Figure scores, for the rest of the tests a quite complex matrix of intercorrelations was obtained. Nonetheless, albeit correlated, different factors were extracted. These tests were not homogeneous in their scores, and probably they depended on different (but relatively "close") "brain systems". For example, it could be hypothetized that performance on the Boston Naming Test and the Information subtest of the WMS (highly correlated, and grouped into the single "verbal knowledge" factor) depend on "closer" (or rather, "common") brain systems, than the Boston Naming Test and, say, the Orientation subtest of the WMS (with a correlation close to zero). It could be supposed that the stronger the correlation between two tests, the higher the commonality of the brain activity supporting their performance should be, and the lower the correlation, the higher the "functional distance" in the brain organization of those cognitive abilities required for their correct performance.

The factor structure of our neuropsychological battery showed a moderate coincidence with the factor structure reported in intelligence factorial research using the WAIS (Cohen, 1957; Matarazzo, 1972). The number of factors that we observed was, however, considerably higher. WAIS Factor I ("verbal comprehension" factor: Information, Vocabulary, Similarities, and Comprehension subtests) might correspond to our Factor V ("verbal knowledge", including the Information subtest of the WMS and the Boston Naming Test). Factor II ("perceptual organization" factor: Object Assembly, Block Design, Picture Completion, and Picture Arrangement subtests) may partially correspond to our Factor II ("nonverbal memory and constructional" factor: WMS Visual Memory subtests and the Rey-Osterrieth Complex Figure, copy and immediate reproduction). Factor III ("freedom of distractibility") measured with Digit-Symbol subtest might partially correspond to our Factor IX ("mental control": WMS Mental Control score). Sometimes a Factor IV (Arithmetics) has been reported in the WAIS factorial analysis (Cohen, 1957); our closest factor could be Factor VIII ("digits").

However, we observed five additional factors: Factor I is a "verbal production" factor (Verbal Fluency subtests and Sequential Verbal Memory Test scores). Factor III represents a "verbal memory" factor (WMS Logical Memory subtests). Factor IV is a "fine movements" factor (Tapping subtests, right and left hand). Factor VI represents a "praxic ability" factor (ideomotor Apraxia Test, left and right hand). Finally, we observed a "verbal delayed memory" factor (Factor VII: Delayed Associative Learning subtest). In brief, we observed one extra factor associated with verbal production ("verbal production" factor); two extra factors associated with memory ("verbal memory" and "delayed associative learning"); and two factors associated with movement control ("fine movements" and "praxic ability" factors). This is understandable taking into account that we tried to cover a wide range of cognitive abilities when our neuropsychology test battery was assembled.

Verbal functions were over-represented in our neuropsychological test battery. Out of nine factors, two (Factor I: "verbal" factor, and Factor V: "verbal knowledge") were associated with verbal functions, while only one (Factor II: "non-verbal memory and constructional factor") was clearly associated with non-verbal functions. Three factors were clearly associated with memory functions (Factor III: "verbal 
memory", Factor VII: "delayed associative learning", and Factor VIII: "digits"). Two factors were associated with motor functions (Factor IV: "fine movements" and Factor VI: "praxic ability"). Finally, one factor was related to maintained attention (Factor IX: "mental control"). Scores in verbal factors are expected to depend (according to our current neuropsychological knowledge) upon some left hemisphere activity, whereas scores in non-verbal factors are expected to depend on right hemisphere activity. In the two motor control factors (Factor IV: "fine movements", and Factor VI: "praxic ability") high and significant correlations were observed for both the right and left hand movements. In consequence, a bihemispheric participation may have been involved. Memory function has been associated with temporal lobe activity, although some asymmetry can be expected (verbal vs non-verbal memory). We observed three verbally based memory factors, and only one non-verbally based (Factor II: "non-verbal memory and constructional factor"). Performance in the Figure Recognition test theoretically is expected to depend upon the activity of those most posterior brain areas; and performance in the WCST has been reported to be impaired in cases of frontal lobe pathology (Heaton, 1981).

Recently, Matarazzo (1992) has emphasized the importance of obtaining a better understanding of the structure of cognitive activity. He considers that neuropsychological tests of the future will provide more sophisticated analyses of the component processes underlying various cognitive functions. Excellent clinical/anatomical correlations (i.e. sensitivity of different neuropsychological tests to different brain pathologies) have been obtained in neuropsychology clinical research. However, our understanding about the structure of the cognitive activity, and its brain organization, remains limited. The need for further analysis of the underlying cognitive structure measured through our current neuropsychological tests is evident.

\section{REFERENCES}

Ardila A and Rosselli M (1992) Neuropsicologia Clinica. Prensa Creativa, Medellin, Colombia.

Ardila A and Rosselli M (in press) Development of language, memory and visuospatial abilities in five- to 12 year-old children using a neuropsychological test battery. Developmental Neuropsychology.

Ardila A, Rosselli M and Puente A (1994) Neuropsychological Evaluation of the Spanish Speakers. Plenum, New York.

Bornstein RA and Chelune GJ (1988) Factor structure of the Wechsler Memory Scale-Revised. The Clinical Neuropsychologist, 2, 107-115.

Cattell RB (1971) Abilities: Their Structure, Growth and Action. Houghton-Mifflin, Boston.

Cohen JA (1957) A factor analytically-based rationale for the Wechsler Adult Intelligence Scale. Journal of Consulting Psychology, 21, 451-457.

Daigneault S, Braun CMJ and Whitaker H (1992) An empirical test of two opposing theoretical models of prefrontal function. Brain and Cognition, 19, 48-71.

De Renzi E (1985) Methods of limb apraxia examination and their bearing on the interpretation of the disorder. In: Neuropsychological Studies of Apraxia and Related Disorders (Ed. EA Roy), pp. 45-64. North Holland, Amsterdam.

De Renzi E and Faglioni P (1978) Normative data and screening power of a shortened version of the Token Test. Cortex, 14, 327-342.

Elwood RW (1991) Factor structure of the Wechsler Memory Scale-Revised (WMS-R) in a clinical sample: A methodological reappraisal. Clinical Neuropsychologist, 5, 329-337.

Goodglass $\mathrm{H}$ and Kaplan $\mathrm{H}$ (1983) Evaluación de las afasias $y$ de transtornos similares, 2nd edn. Editorial Médica Panamericana, Buenos Aires.

Guilford JP (1967) The Nature of Human Intelligence. McGraw-Hill, New York.

Guilford JP (1968) Intelligence has three facets. Science, 160, 615-620.

Guilford JP and Hoepfner R (1971) The Analysis of Intelligence. McGraw-Hill, New York.

Haut JS, Haut MW, Callahan TS and Franzen MD (1992) Factor analysis of wide range of assessment of memory and learning (WRAML) scores of a clinical sample. The 12th Annual Meeting, National Academy of Neuropsychology, Pittsburgh, PA.

Heaton RK (1981) Wisconsin Card Sorting Test: Manual. Psychological Assessment Resources, Odessa, FL.

Kaplan E, Goodglass $\mathrm{H}$ and Weintraub S (1983) The Boston Naming Test. Lea and Febiger, Philadelphia.

Kolb B and Whishaw I (1990) Fundamentals of Human Neuropsychology, 2nd edn. WH Freeman, New York.

Lezak MD (1983) Neuropsychological Assessment. Oxford University Press, New York.

Matarazzo JD (1972) Wechsler's Measurement and Appraisal of Adult Intelligence. Oxford University Press, New York.

Matarazzo JD (1992) Psychological testing and assessment in the 21 st century. American Psychologist, 47, 1007-1118.

Osterrieth PA (1944) Le test de copie d'une figure complexe. Archives de Psychologie, 30, 206-356.

Ostrosky F, Canseco E, Quintanar L, Navarro E and Ardila A (1985) Sociocultural effects in neuropsychological assessment. International Journal of Neuroscience, 27, 53-66.

Ostrosky F, Quintanar L, Canseco E, Meneses S, Navarro E and Ardila A (1986) Habilidades cognoscitivas y nivel sociocultural. Revista de Investigación Clinica (Mexico), 38, 37-42.

Poeck K (1986) The clinical examination of motor apraxia. Neuropsychologia, 24, 129-134.

Reitan MR and Davidson LA (1974) Clinical Neuropsychology: Current Status and Applications. Wiley, New York.

Roid GH, Prifitera A and Ledbetter M (1988) Confirma- 
tory analysis of the factor structure of the Wechlser Memory Scale-Revised. Clinical Neuropsychology, 2, 116-120.

Rosselli M and Ardila A (1991) Las apraxias. Acta Neurologica Colombiana, 7, 25-32.

Spreen O and Strauss E (1991) A Compendium of Neuropsychological Tests. Oxford University Press, New York.

Taylor EM (1959) The Appraisal of Children with Cerebral Deficits. Harvard University Press, Cambridge, MA.
Wechsler D (1945) A standardized memory scale for clinical use. Journal of Psychology, 19, 87-95.

Wechsler D (1987) Manual for the Wechsler Memory ScaleRevised. Psychological Corporation, San Antonio, TX.

Wilhem KL and Franzen MD (1992) A factor analysis of several brief neuropsychological instruments. The 12th Annual Meeting, National Academy of Neuropsychology, Pittsburgh, PA. 


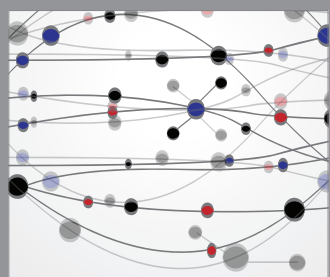

The Scientific World Journal
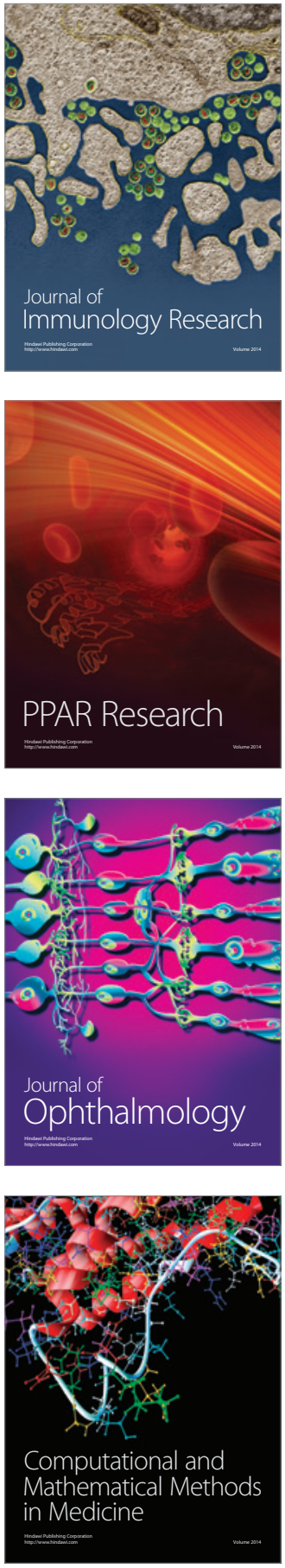

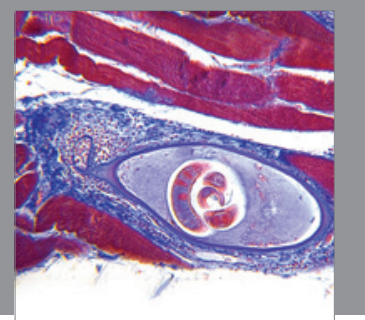

Gastroenterology

Research and Practice
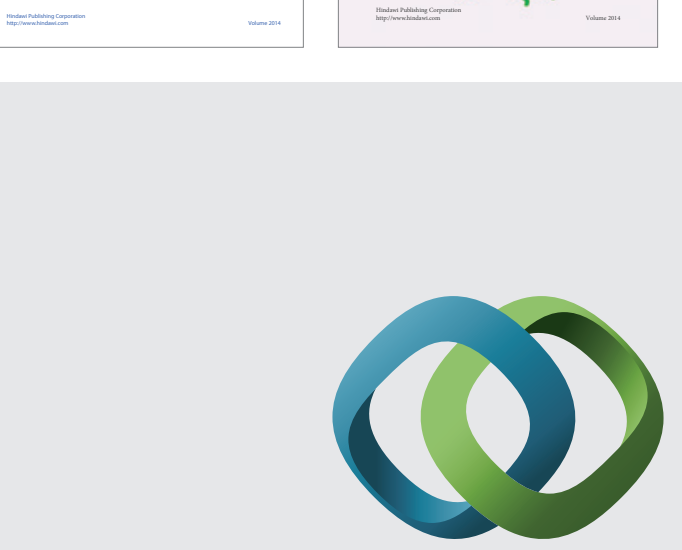

\section{Hindawi}

Submit your manuscripts at

http://www.hindawi.com
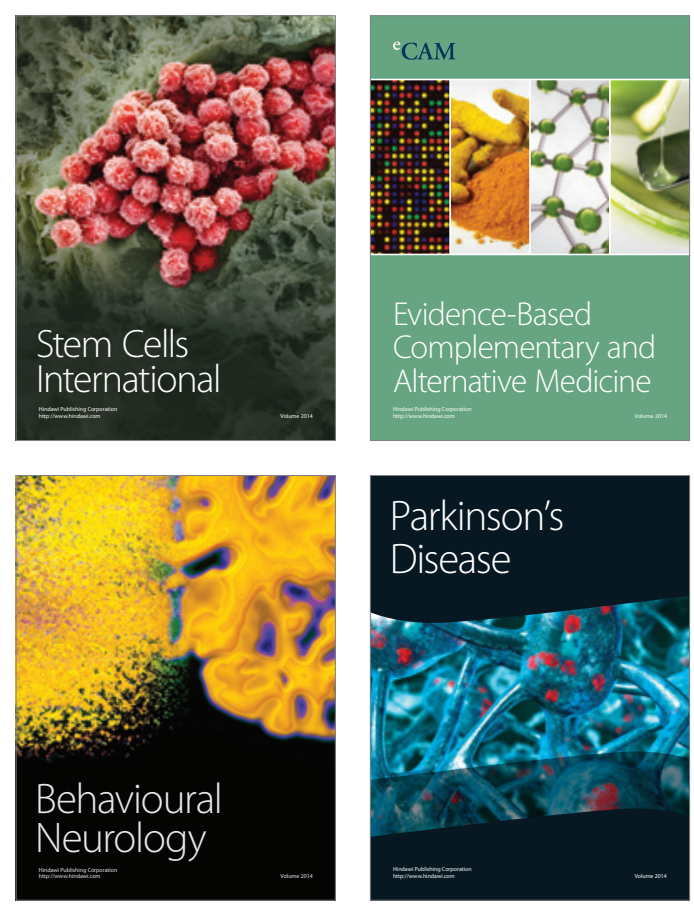

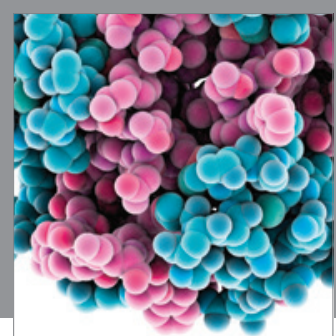

Journal of
Diabetes Research

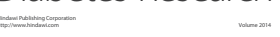

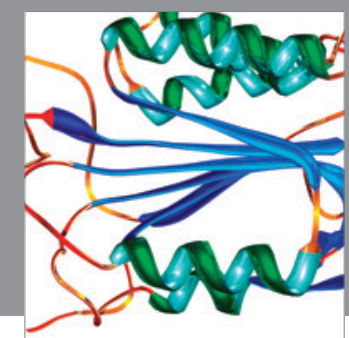

Disease Markers
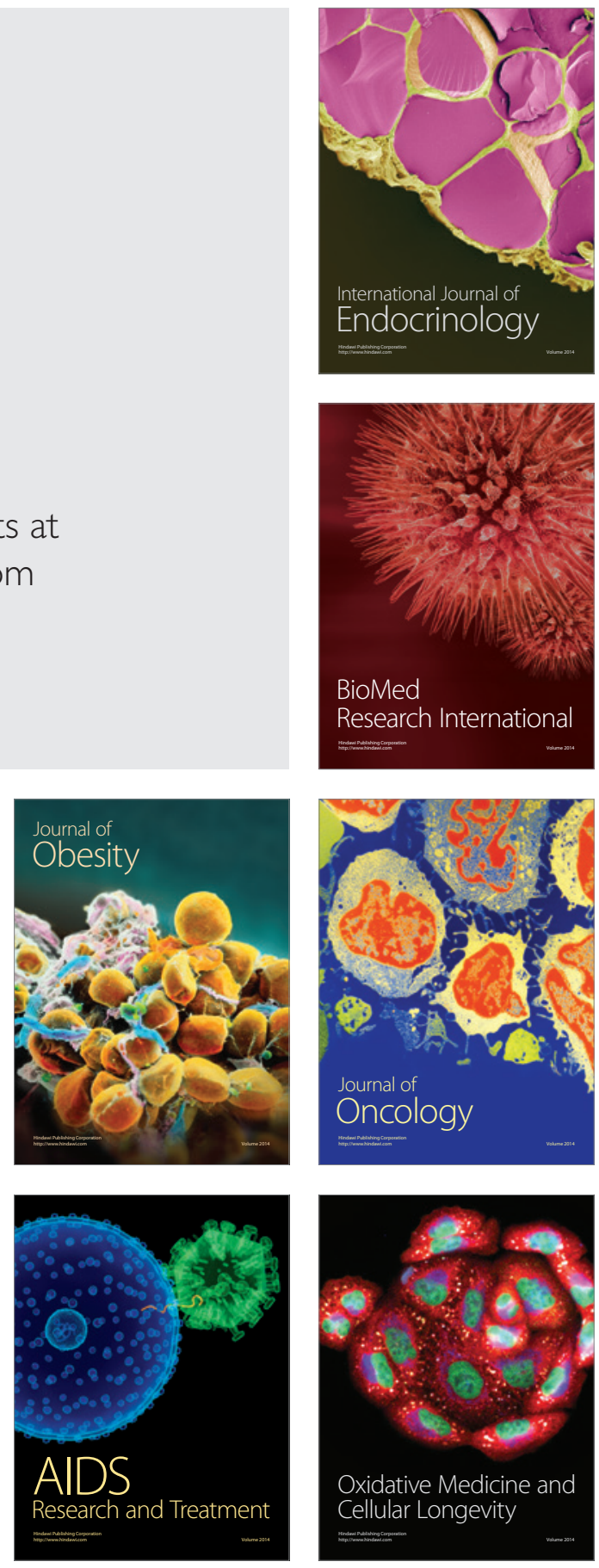